\title{
E-Governance for Good Governance: Experiences from Public Service Delivery
}

\author{
Mohammad Abdul Salam \\ Upazila Nirbahi Officer, Jamalpur Sadar \\ Jamalpur-2000, Bangladesh
}

\begin{abstract}
E-governance is widely accepted as an effective tool of service delivery and equated with good governance by all developed countries in general and developing countries like Bangladesh in particular. The core purpose of this study is to validate the e-governance for good governance. The quantitative research approach was conducted. Data was collected using self-administered questionnaire from random samples drawn from the population of service providers and service receivers from four different DESCs of Bangladesh. The standard of service, choice \& consultation, courtesy \& consultation, entrance \& information, and value for money variables were used to assess the quality of service while accountability, transparency, effectiveness, responsiveness, and rule of law were used to analysis the effective measures for good governance. The study results revealed that the DESC provides public services efficiently and e-governance is positively correlated to good governance promises impending to validation of hypothesis.
\end{abstract}

\section{General Terms}

DESC (District E-Service Centers), UISC (Union Information \& Service Centers), ICT (Information \& Communication Technology), IT (Internet Technology)

\section{Keywords}

e-governance, good governance, public service delivery

\section{INTRODUCTION}

Internet Technology (IT) is creating new desires and opportunities among people for quality service. The expression of e-government indicates the usage of IT by the agencies to provide better citizen services. Moreover, egovernment is being considered as powerful tool to reducing cost, enhancing revenues, and improving public service delivery [1]. Harris (2000) stated, e-governance intents to ensure the efficiency, accountability and transparency in the functioning of government and show the way of good governance [2]. According to Heeks (2001), IT simplifies the administrative process, facilitates the performance more effectually, and transforms a relationship within society [3]. He also pointed out three main contributions of e-governance like improving government processes (e-administration), connecting citizens (e-services), and building external interactions (e-society).

Ghosh et al. (2004) conceptualizes e-service as interactive information service among the service providers, service recipients and agencies [4]. The e-service is very different from traditional service, which is based on interactive information flow between customers and service providers [5]. In this process, the information technology is critical for customer satisfaction. With the aspire to provide the public services at the doorsteps of citizens and connecting the people, Bangladesh government has set-up e-service centers at Union, Upazila, and District level as part of e-governance scheme. The government has tried to deliver the public services through the e-service centers. The current study is tried to assess the District E-Service Centers ${ }^{1}$ in Bangladesh in terms of the public service delivery. Moreover, the research is attempt to establish linkage between the e-governance and good governance

UNDP (2007) says that e-governance can provide basic tools and mechanisms for poor communities to hold both policy makers and service providers accountable for a sustained supply of services [6]. Thus, it becomes important to view the status of e-governance. Kasubiene and Vanagas (2007) believe that since e-governance is a new research area and egovernance service quality aspect is even more in need for research, despite its importance in the public sector with due regard to the customer's perceptions and expectations from a service delivery point of view [7]. The motivations for egovernment and e-services have been well documented in contemporary literature. The two terms, e-government and eservices can be viewed from a supply and demand perspective. On the demand side, the desire for electronic services or the level of e-service use by people can be used to rationalize engaging in e-government, while on the supply side, e-government can also be a means to get citizens to access e-services.

The current study ranges from the dimensions and attributes of e-service quality, the level of citizen satisfaction as well as relationship between e-governance to good governance. The outcome of this research will help e-government administrators $^{2}$ to make substantial initiatives for obtaining the goal of good governance through various ways. The results obtained from this research study will be helpful for government officials to know the contribution of egovernment towards good governance. The information obtained from the research will provide useful guidance for managers of e-government in improving the application of egovernment. Consequently, the knowledge obtained from the outcome of this research can be used in future e-government initiatives by the government.

The research is attempts to identify the linkage between the factors responsible for creating conducive environment for effective implementation of e-governance and factors relating to good governance.

\footnotetext{
${ }^{1}$ DESC inaugurated by the GoB in 2010 to better service delivery of the citizens

${ }^{2}$ Policy makers who take decision and policy implementers' who are close to the citizens
} 


\section{METHODOLOGY}

With the aim to determine the relationship between dependent and independent variables the quantitative research was apprehended. The relationship was expressed between variables using effect statistics such as correlations, relative frequencies or means and percentage differences [8]. In this research, out of 64 DESC of Bangladesh four has been selected to study named as Mymensingh, Shariatpur, Madaripur and Dhaka as category A, B, C and special category respectively. The service centers has been selected through the cluster sampling method.

\subsection{Sampling Design}

The quota sampling method was followed in this study. In this step, 16 from each and total 64 respondents from four service centers were selected. Purposive sampling method followed for respondent selection. The identical response categories were used for several items intended to measure a given variable and each item has scored in a uniform manner. The level of good governance was graded by using five point Likert scales [9]. The scale has five level of grading from 5 to 1 , where 5 denoted the highest grading score while 1 referred the lowest.

\subsection{Data Analysis}

Different types of data collection procedure for this research were conducted to collect data. The primary data were collected by using structured questionnaire from key respondents and asking set of questions from experts' interview. The secondary data was gathered through content analysis from the research articles, textbooks and dailies while documents survey scheme from various webpage. The data was analyzed by using simple statistical tools like tabulation, frequency, percentage, arithmetic means and standard deviations. A relationship between the dependent and independent variables were analyzed through Regression Analysis.

\subsection{Performance Measures}

Good governance performance is measured by using six indicators like accountability, transparency, effectiveness, responsiveness, rule of law and participation. Under the heading of each indicator, two questions are framed in the questionnaire for grading the level of each indicator and comparison with the traditional system. The quantification process is introduced for good governance performance measures. The good governance performance $\left(\mathrm{GG}_{\mathrm{PM}}\right)$ is calculated by the subsequent equation.

$$
\begin{aligned}
\mathrm{GG}_{\mathrm{PM}}= & \log \left(A C_{h}-A C_{m}\right)+\log \left(T R_{h}-T R_{m}\right)+\log \left(E F_{h}-E F_{m}\right) \\
& +\log \left(R E_{h}-R E_{m}\right)+\log \left(R L_{h}-R L_{m}\right)+\log \left(P A_{h}-P A_{m}\right)
\end{aligned}
$$

$\mathrm{GG}_{\mathrm{PM}}=\mathrm{E}$-governance performance measures

$A C_{h}=$ highest value of accountability

$A C_{m}=$ mean value of accountability

$T R_{h}=$ highest value of transparency

$T R_{m}=$ mean value of transparency

$E F_{h}=$ highest value of effectiveness

$E F_{h}=$ mean value of effectiveness

$R E_{h}=$ highest value of responsiveness

$R E_{m}=$ mean value of responsiveness

$R L_{h}=$ highest value of rule of law

$R L_{m}=$ mean value of rule of law

$P A_{h}=$ highest value of participation

$P A_{m}=$ mean value of participation

The value of $\mathrm{GG}_{\mathrm{PM}}>1$ (Performance is good) or $\mathrm{GG}_{\mathrm{PM}}<1$ (Performance is not good).
Further, the good governance was analyzed by overall performance of government in enhancing good governance capability by adding up the score for each feature was verified for selected service centers and the study assessed the effectiveness e-government in enhancing the good governance in relation with the traditional government in addition to analyzed the level of good governance effectiveness.

\section{RESULTS AND FINDINGS}

The effectiveness of good governance is measured on accountability, transparency, effectiveness, responsiveness, rule of law, and participation indicators. The assessment was done through the enhancement level, Gap analysis, and Regression co-efficient.

\subsection{Enhancement Level}

In this research the effectiveness of good governance is analyzed for e-government. In this pace of data analysis, the total grading scores of all indicators of good governance was determined. In every aspects of good governance, the level of effectiveness was raised in e-government era compare to traditional government. The enhancement level illustrated in Table-1, the effectiveness has enhanced $50.00 \%$, which demonstrated a fair level of enhancement towards good governance where can do much better. Moreover, the accountability has enhanced $40.16 \%$, transparency has enhanced $39.38 \%$, responsiveness has enhanced $37.81 \%$, and rule of law has enhanced $39.53 \%$, which demonstrated a poor level of enhancement. However, the participation enhanced only $29.22 \%$, which demonstrated very poor level of enhancement.

Table 1. Level of enhancement of good governance

\begin{tabular}{|l|c|c|}
\hline $\begin{array}{l}\text { Governance } \\
\text { Indicators }\end{array}$ & $\begin{array}{c}\text { Enhancement } \\
\text { Level }\end{array}$ & $\begin{array}{c}\text { Level of } \\
\text { Effectiveness }\end{array}$ \\
\hline Accountability & $40.16 \%$ & Poor \\
\hline Transparency & $39.38 \%$ & Poor \\
\hline Effectiveness & $50.00 \%$ & Fair \\
\hline Responsiveness & $37.81 \%$ & Poor \\
\hline Rule of Law & $39.53 \%$ & Poor \\
\hline Participation & $29.22 \%$ & Very poor \\
\hline
\end{tabular}

Heeks (2001) studied the effect of new information and communication technologies and how it can make a significant contribution to the achievement of good governance goals [3]. Pitman (2006) claimed that egovernment is the way for governments to realized improved efficiency and function [10]. The current findings of the research also pointed out that e-government initiative like DESC had an insignificant improvement towards good governance in the case of service delivery required more commitment. However, there is a room for development in participation

\subsection{Gap Analysis}

The contour (see Figure-1) showed the efficacy of each indicator of good governance and its perception among the service providers and receivers. The figure demonstrated a remarkable gap between the service provider and receiver perception in the case of transparency and effectiveness. The perception of receivers and providers was almost same for 
accountability, responsiveness, rule of law, and participation. Citizen perception about the transparency of good governance through e-service was $73.13 \%$ less than service provider view, $76.25 \%$. Case of effectiveness also showed a gap between the perceptions of citizens $(80.63 \%)$ and the service providers $(82.81 \%)$. The result indicated that there are necessities of gap minimizing.

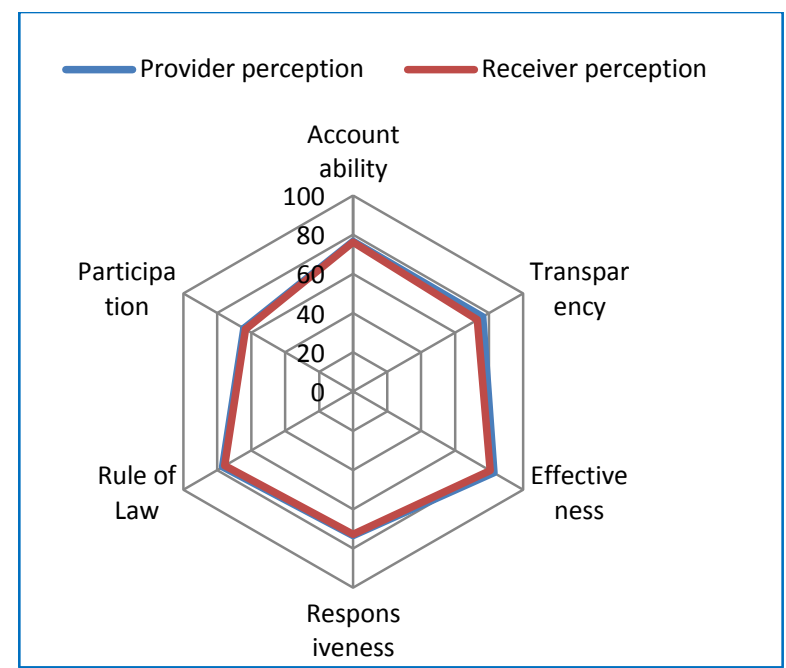

Figure 1. Service providers and receivers perception on good governance efficacy

\subsection{Regression Coefficients}

The Figure- 2 represented the regression line which drawn by the variables and proved e-governance positively correlated with good governance. The good governance is ensuring with the development of e-governance performance.

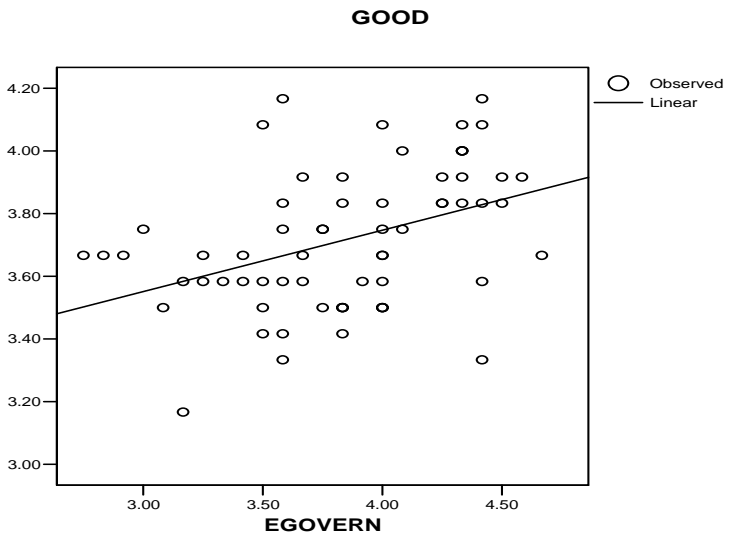

Figure 2. Regression line for e-governance and good governance

\section{ANALYSES AND DISCUSSION}

The key findings were found after the data analysis of egovernance, citizen satisfaction and good governance that presented under correlation analysis and performance measure sub-heads. The discussion was done on the basis of research objectives.

\subsection{Correlation Analysis}

The Pearson Correlation was conducted to find out the relationship among all variables like e-governance, citizen satisfaction and good governance and to determine the degree of their correlation. The results of Pearson Correlation endow with an understanding the direct relationship among the key variables like e-governance, citizen satisfaction and good governance. The correlation values were $0.645,0.567$ and 0.410 (see Table-2) where all showed the moderately positive correlation among the key variables. According to the Pallant (2001), the correlation among the electronic governance, satisfaction level and good governance were significant (less than 0.70 ) that validate the current study [11].

Table 2. Correlation matrix among independent and dependent variable

\begin{tabular}{llll}
\hline Major Variables & EG & SL & GG \\
\hline E-Governance & 1 & & \\
Satisfaction Level & $.567^{* *}$ & 1 & \\
Good Governance & $.410^{* *}$ & $.645^{* *}$ & 1 \\
\hline${ }_{* *}^{* *}$ & & & \\
\hline
\end{tabular}

Correlation is significant at the 0.01 level (2-tailed)

E-government was regarded as powerful tool in hands of government for reducing cost, enhancing revenues, improving delivery of public services [1]. Field et al. (2004) argued that e-service can play a critical role in improving the services quality delivered to its customers as it can achieve survival, increase satisfaction and trust and then generate the competitive success for organizations [12]. Harris (2000) purported to ensure the efficiency, accountability and transparency in the functioning of government and show the way of good governance [2]. The current research appropriated the above research findings.

\subsection{Performance Measures}

In this section, the performance of DESC was measured regarding the e-governance service, level of citizen satisfaction and the good governance premises.

The good governance premises performance calculated through the following equation where the highest standard value and the mean value of each indicator were considered:

$\mathrm{GG}_{\mathrm{PM}}=\log \left(\mathrm{AC}_{\mathrm{h}}-\mathrm{AC}_{\mathrm{m}}\right)+\log \left(\mathrm{TR}_{\mathrm{h}}-\mathrm{TR}_{\mathrm{m}}\right)+\log \left(\mathrm{EF}_{\mathrm{h}^{-}}\right.$

$\left.\mathrm{EF}_{\mathrm{m}}\right)+\log \left(\mathrm{RE}_{\mathrm{h}}-\mathrm{RE}_{\mathrm{m}}\right)+\log \left(\mathrm{RL}_{\mathrm{h}}-\mathrm{RL}_{\mathrm{m}}\right)+\log \left(\mathrm{PA}_{\mathrm{h}}-\mathrm{PA}_{\mathrm{m}}\right)$

$=\log (5-3.81)+\log (5-3.70)+\log (5-4.05)+\log (5-3.65)+\log (5-$

3.80) $+\log (5-3.27)$

$=\log 1.19+\log 1.30+\log 0.95+\log 1.35+\log 1.20+\log 1.73$

$=0.08+0.11-0.02+0.13+0.08+0.24$

$=0.62($ less than 1$)$

Analysis showed that the DESC performance value regarding e-governance service was 0.33 , level of citizen satisfaction was 0.49 and the good governance premise was 0.62. All values of DESC performance were less than 1 (targeted vale) that indicated meager performance that indicates there is a scope for further development.

\section{CONCLUSION}

\subsection{Summary}

The e-governance is to support and simplify governance for both the service providers and service receivers. The key objective of this study was to explore the relation between egovernance and good governance. The study has revealed that the DESC provides public services efficiently, the e-service delivery has positive impacts on citizen satisfaction and the egovernance initiative leads to good governance promises. But, the performance measures of DESC regarding the e- 
governance services, level of citizen satisfaction and the good governance promises revealed its scanty accomplishment. Thus for effective e-governance service delivery needs further improvement as desire of the citizens.

The study proved that e-government is facts for the way to good governance through the validation of hypothesis like eservice centers are positively related with effective egovernance service, e-governance services have a positive impact on enhancing citizen satisfaction and e-governance is positively correlated to good governance promises.

The role of e-governance in improving service delivery and quality and the impact that has on customer satisfaction in the context of a small developing country like Bangladesh. It is seen in this research that e-governance has the potential to improve service delivery and customer satisfaction. It is to minimize corruption, provide efficient service, ensure accountability and intensify the transparency through the easy accessibility, greater convenience and altitude of interaction. There is a gap between the perception of e-service delivery by service providers and expectation of service quality by service receivers. There is an urgent need in Bangladesh to apply egovernance for minimizing the gaps, improve the service quality and also to build-up citizen-centric service delivery.

\subsection{Policy Implications}

It may conclude that proper implementation of e-government tools may have the positive role to ensure good governance in service delivery if we follow some rules;

a. A central coordinating body must be institutionalized that can coordinate and execute the necessary reforms to make achievement of the citizen-centric e-service or egovernance.

b. The competitive pricing is essential along with raising awareness among the people. In this case, electronic and print media can play their roles.

c. Institutional restructuring, reforms and capacity building also required providing government services.

d. Establishing the adequate data privacy and security provisions that ensure the confidentiality and to prevent unauthorized access.

\subsection{Limitations}

The study has clear limitations that could provide openings for further study. The methodology could look to expand by conducting focus groups involving citizens or users, apart from administrative personnel and IT managers. However, the views of service receivers could be accrue for further study.

\section{ACKNOWLEDGMENTS}

My special thanks to the authority of the Institute of Governance Studies, BRAC University, Bangladesh for overall support for academic and this research work. I wish to express my deep gratitude and sincere appreciation to Dr. Md.
Rizwan Khair, former Director, Institute of Governance Studies, BRAC University, Bangladesh. I am also acknowledging the inspiration from Dr Md. Zohurul Islam, Deputy Director of Bangladesh Public Administration Training Centre, Dhaka.

\section{REFERENCES}

[1] Saeed, M. (2012). E-governance service delivery-an assessment of community information center model in India. Interdisciplinary Journal of Contemporary Research in Business, 3(9): 1344- 1359.

[2] Harris, B. (2000). E-Governance. Retrieved April 15, 2011 from<http:/www.iadb.org>

[3] Heeks, R. (2001). Understanding e-governance for development, i-government working paper series. Institute for Development Policy and Management, University of Manchester, No 11.

[4] Ghosh, S., Surjadjaja, H., and Antony, J. (2004). Optimization of the determinants of eservice operation. Business Process Management Journal, 10(6): 616-636.

[5] Li, H. and Suomi, R. (2007). Evaluating electronic service quality: a transaction process based evaluation model. In Remenyi, Dan (editor) Proceedings of ECIME 2007. The European Conference on Information Management and Evaluation. Montpellier, France 2021. September 2007, pp.331-340.

[6] UNDP. (2007). Pro-Poor Public Ser-vice Delivery with ICTs (E-Note 11), "Making local e- governance work towards achieving the millennium development goals.

[7] Kasubiene, L. and Vanagas, P. (2007). Assumptions of egovernment services quality evaluations. Engineering Economics, 5(55): 68-74.

[8] Creswell, J. W. (2003). Research design: qualitative, quantitative and mixed methods approach $\left(2^{\text {nd }} e d\right)$, Thousand Oaks, Calif.: Sage.

[9] United Nations Development Programme (UNDP). (2003). The urban governance initiatives (TUGI). Environment \& Urbanization, 15(1): 159-169.

[10] Pitman, A. (2006). Achieving better government outcomes efficiently and effectively via e- government, Microsoft Corporation.

[11] Pallent, J. (2007). SPSS Survival Manual: A Step by Step Guide to Data Analysis using SPSS for Windows, England, McGraw.

[12] Field, J.M., Heim, G.R. and Sinha, K.K. (2004). Managing quality in the eservice system: Development and application of a process model. Production and Operations Management, 13(4): 291-306. 